\author{
JAMES OLES
}

\title{
Olivier Debroise (1952-2008)
}

A UNQUE SEA DIFÍcIL creerlo ahora, cuando llegué a México en el verano de I990 — como estudiante de doctorado en Yale_-, había relativamente poca comunicación entre los dos países, por lo menos en el ramo del arte moderno/contemporáneo. Fue justo antes del TLC y de la inauguración de Esplendores de Treinta Siglos, de la internacionalización de los coloquios del Instituto de Investigaciones Estéticas bajo la dirección de Rita Eder, y, claro está, mucho antes de la existencia de Google... (sólo hay que recordar que la primera sesión de la College Art Association dedicada exclusivamente al arte latinoamericano no prehispánico tuvo lugar en febrero de ese mismo año). Edward Sullivan me había puesto en contacto con Juan Soriano, Mariana Pérez Amor y Miguel Cervantes, pero en una larga entrevista, Karen Cordero (que había estudiado su posgrado en la misma universidad) me abrió mucho el panorama con una larga lista de nombres. Ésta incluía el del autor de Diego de Montparnasse ( I979) y de Figuras en el trópico (I982) — títulos que me eran desconocidos_- un señor que yo tenía que conocer, que sabía todo sobre Abraham Ángel y la fotografía, y que lideraba el equipo que trabajaba en ese momento en un "gran sueño" para el Museo Nacional de Arte (lo que sería Modernidad y Modernización en el Arte Mexicano, I920-1950)... Poco después, tras muchas llamadas, finalmente aceptó darme una entrevista: fue el momento perfecto, porque todo estaba a punto de estallar, y sus obras, ideas y proyectos formaron parte inseparable de tal cambio, de la profesionalización del estudio del arte mexicano, de su cada vez mayor relevancia en el escenario mundial. A su muerte, hubiera sido difícil encontrar un graduate student grin- 
go, por verde que fuera, con interés en el arte mexicano del siglo $\mathrm{xx}$, que no viera a Olivier Debroise como inevitable punto de referencia.

Bautizado con un largo nombre casi aristocrático que jamás usó —Olivier Marie François Edgar Maurice Debroise Gigout— nació en Jerusalén en I952, lo cual confundió a muchos acerca de sus verdaderos orígenes, aunque le permitió declarar cierta solidaridad con los palestinos. Su padre fue un importante diplomático francés: arabista, amigo de De Gaulle, asignado a Siria en la década de los años veinte, al Vaticano durante la segunda guerra mundial; figura clave en Polonia, Argelia y Marruecos en los años cincuenta y sesenta, que terminó su carrera cómodamente en Brasil y Costa Rica... un personaje casi novelístico que hablaba poco de sus andares profesionales, que su hijo nunca conoció tan bien. A Olivier no le gustó mucho esa vida formal y peripatética que le llevó del Liceo Franco Brasileiro en Río (1959) al Liceo Franco Mexicano en el Distrito Federal ( $197 \mathrm{I}$ ), pero cuando finalmente decidió quedarse en México a mediados de los años setenta, ya tenía una formación cosmopolita y era escéptico del nacionalismo burdo, lo cual le ayudaría mucho años después en su práctica como historiador y crítico. En ese tiempo, el efecto económico de su rechazo (casi) total de las reglas burguesas - hay que acordarse que aunque estudió brevemente en varias universidades en Francia y México, quedó lejos de recibir su licenciatura- le sensibilizó a la vida precaria de muchos artistas contemporáneos: había vivido como ellos alguna vez, algo no siempre cierto en el campo de la crítica. Hasta 2004, cuando aceptó ser curador del programa de adquisiciones del (futuro) Museo Universitario Arte Contemporáneo (MUAC), se había mantenido siempre a una distancia saludable de las instituciones: el clásico hombre freelance.

$\mathrm{Su}$ background "globalizado" antes de la globalización (Francia, Polonia, Marruecos, Brasil, México) facilitó su rol como traductor de culturas: trabajó por años como traductor simultáneo, profesión intensa, incluso en Los Pinos durante el sexenio de López Portillo. Fue traductor simbólico de toda una cultura que rápidamente asimiló, pero que también podía mirar con distancia analítica. Aunque empezó con algo de timidez a través de su participación como cocurador de El Corazón Sangrante, una exposición realizada para el Institute of Contemporary Art de Boston en I99I, la pronta creación de Curare, las becas Rockefeller, los viajes, las conferencias y las pláticas lo convirtieron en un torbellino trilingüe, forjando todo tipo de alianzas con sus colegas en los Estados Unidos, Canadá, Europa, Argentina y más allá: un ser fundamental —aunque obviamente, lejos de ser el único — en la expansión e internacionalización del antiguo mundo del arte mexicano. 
Hay mucho que decir sobre la larga —si abruptamente interrumpida el 6 de mayo de 2008 - carrera profesional de Olivier, de sus trabajos terriblemente solitarios y de otros festivamente colectivos, aunque son imposibles de reseñar en tan pocas palabras. Publicó tres novelas (y tenía dos más en camino): De todas partes, ninguna (I984); Lo peor sucede al atardecer (I990); y Crónica de las destrucciones (1998), ganadora del Premio Colima, una complicada exploración de las primeras décadas novohispanas, basada en una investigación exhaustiva, casi obsesiva. No solamente aprendió náhuatl y leyó todo sobre la Conquista, sino que visitó (bueno, visitamos) hasta los más remotos complejos monásticos de mediados del siglo Xvi (esa novela tuvo, como secuela, un brillante ensayo académico sobre los murales fronterizos de San Miguel Ixmiquilpan, publicado en 1994). También dedicó mucha energía a la evanescente pero crucial labor de crítica de arte, en particular para La cultura en México/Siempre! (I979-I984), La Jornada (I984-I992) y Reforma (20002004), escribiendo sobre temas variados, desde reseñas de muestras — de Alice Rahon y Gabriel Orozco, entre otros- hasta devastadoras críticas de la política cultural del Estado: alguien, algún día, tendrá que releerlos, revisarlos, recopilarlos...

A pesar de algunos planes truncados en los años setenta, cuando estudió cinematografía y conoció a Jodorowsky, llegó más adelante a ser cineasta también: uno de sus mejores éxitos personales fue Un banquete en Tetlapayac (2000), un denso largometraje que utiliza varios géneros (narrativa, documental, performance, simposio) para meditar sobre el paso de Eisenstein por México a principios de los años treinta. Relacionada con sus múltiples experiencias como líder de equipos curatoriales (museográficos sí, pero también Curare, CANAIA y Teratoma), la película — para la cual ganó una beca Guggenheimfue sobre todo una experiencia, una manera de juntar personajes muertos y vivos, amigos y desconocidos, y convivir con todos los que participamos para forjar a través del grupo una sinergia que pudo dirigir mas no controlar. $U n$ banquete en Tetlapayac es una película complicadísima, sui generis pero repleta de citas, rigurosamente histórica y a la vez poéticamente especulativa, gay y straight, fácil e imposible de entender, bien hecha y mal hecha, y claro está, realizada con muy poco presupuesto. Fue emblemática de la visión que Olivier tenía de su profesión: uno tenía que hacer demasiado, porque había demasiado que hacer.

¿Pero cómo entender o evaluar su papel en la historiografía reciente en México? Sobre todo, la importancia reside en su trabajo como crítico/histo- 
riador/curador del arte mexicano tanto moderno como contemporáneo, dos campos bastante diferentes que requieren de visiones y negociaciones distintas, pero que mezclados resultan aún más fructíferos. Sin haber sido formado en una escuela, participó en la destrucción del formalismo y de los discursos nacionalistas que cercaron los estudios del arte moderno mexicano en una época posrevolucionaria caduca que tardó tanto en expirar. Aunque empezó (lógicamente) con un interés en los años parisienses de Rivera, luego optó por la generación que había quedado oculta por el muralismo. En los años ochenta y noventa, con la ayuda de algunos listos sobrevivientes - y sobre todo, nutrido por su cercana amistad con Lola Álvarez Bravo- redescubrió a Alfonso Michel, desmitificó a Abraham Ángel, catalogó la obra de Antonio Ruiz, narró cuentos maravillosos sobre Angelina Beloff, María Izquierdo y Blanca Luz Brum... Entre sus estudios más importantes lucen Figuras en el trópico (una nueva y extendida versión, terminada antes de su muerte, en espera de su publicación) y la revisión crítica de la obra de David Alfaro Siqueiros de los años treinta, Retrato de una década (1996), además de sus innumerables trabajos sobre la historia de la fotografía mexicana que culminaron con la publicación de las distintas ediciones de Fuga mexicana: un recorrido por la fotografia en México.

Sobre su importancia en el mundo del arte contemporáneo, como críticoparticipante-instigador-curador-cuate, hay tanto que decir que otros lo tendrán que precisar: aparte de las exposiciones o ensayos que involucraban desde a Adolfo Patiño, Carla Rippey y Javier de la Garza, hasta Francis Alÿs, Silvia Gruner y Melanie Smith, hasta otros que cada vez eran más y más jóvenes, además de proyectos foráneos como zangular e insite97, hay que resaltar su último gran experimento: La Era de la Discrepancia. Arte y Cultura Visual en México, 1968-1997, un proyecto ligado a la creación de una colección de arte para el nuevo MuAC, una labor —o más bien, una responsabilidad pública a largo plazo-, que muy pocos en el gremio, y menos los que ven todo a corto plazo, entendieron bien. La Era de la Discrepancia fue discutida en equipo, bilingüe para alcanzar públicos internacionales, historicista y contemporánea a la vez, controvertida y problemática — ¿cómo podría no haberlo sido?-, pero brillante, atrevida y sobre todo, realizada: muchos sueñan en hacer algo perfecto, pero Olivier hizo lo que pudo en el mundo real y lo volvió a hacer, hasta el cansancio.

Los abruptos deslices intelectuales que definían su vida profesional — ¿tenía algo que ver con esa falta de verdaderas raíces cuando era niño? - le permitían 
evitar el aburrimiento, el horror vacui. Pocos de sus colegas manejaron un abanico de intereses tan distintos el uno al otro o forjaron carreras tan multifacéticas: más que novelista o historiador fue de los grandes pensadores mexicanos de finales del siglo pasado y principios del actual, tan mexicano, es decir, como Luis Cardoza y Aragón o Raquel Tibol o tantos otros refugiados, huyendo de lo que fuera. Tuvo una visión expansiva de su trabajo y del campo en que trabajaba: abrió incontables puertas para todos los que le seguimos. Y siempre tomaba todo con una seriedad terrible, trabajando ahora en oposición a las instituciones (Curare se estableció cuando el Consejo Nacional para la Cultura y las Artes priísta permitía poca experimentación en los museos) y dentro de ellas, como al final de su vida, en la Universidad Nacional Autónoma de México.

Olivier Debroise fue un símbolo de la necesidad de tomar una posición ética como agente cultural, y nos recordaba que no estábamos trabajando ni en una torre de marfil ni en un circo, que lo que hacíamos sí importaba. Cuando decidió comprometerse, fue total e intenso, una postura que aumentó la pasión pero también el estrés, creó éxitos y también fracasos, forjó amistades y enemistades. Fue una fuerza y un nexo, conciencia, contrapunto, contrapeso, contrincante... pero sobre todo, fue un cartógrafo visionario: otros llegarían después a trazar los detalles, a llenar los huecos, a pintar los dibujitos o incluso, a corregir los errores, pero Olivier cambió por completo la interpretación del terreno. \$े 